\title{
Prevención y manejo del sangrado en cirugía cardíaca
}

\author{
Dres. Fernando Delgado1, Washington Machado', Gonzalo Machado²
}

\section{Resumen}

Todo procedimiento quirúrgico supone grados variables de agresión. La cirugía cardíaca (CC) con el uso muchas veces necesario de la circulación extracorpórea (CEC), impacta particularmente sobre múltiples sistemas orgánicos. En el presente trabajo, se analizará su repercusión sobre la hemostasia.

El sangrado es una de las complicaciones más frecuentes y con mayor morbimortalidad durante el posoperatorio de CC. Aunque de causa multifactorial, adquieren especial relevancia la técnica quirúrgica, el tiempo de CEC y las enfermedades preexistentes.

La aparición de nuevos fármacos procoagulantes y sistemas de monitorización de la hemostasia, junto al uso de protocolos de manejo con buena evidencia pero baja adherencia, no han logrado hasta el momento disminuir el uso de hemocomponentes.

En esta revisión analizamos las recomendaciones actuales para el manejo del sangrado en CC, su prevención a través de la optimización preoperatoria del paciente, la estratificación del riesgo, el sostén de la hemostasia intraoperatoria y el tratamiento de las complicaciones hemorrágicas posoperatorias.

Palabras clave: SANGRADO POSOPERATORIO

PROFILAXIS

MANEJO

\section{Management of bleeding in the cardiac surgery setting}

\section{Summary}

Any surgical procedure is detrimental to the body. Cardiac surgery with the necessary use of cardiopulmonary bypass particularly impacts on multiple systems. In this review, emphasis will be placed on its impact on hemostasis.

Bleeding is one of the most frequent complications and with the highest morbidity and mortality in these patients. Although it is caused by a number of factors, the surgical technique, the cardiopulmonary bypass time and the pre-existing diseases acquire special relevance.

The appearance of new procoagulant drugs and systems for monitoring hemostasis, the use of management protocols, with good evidence but low adherence, have so far not been able to reduce the use of blood components.

In this review we analyse the current recommendations for the management of bleeding in cardiac surgery, its prevention through the preoperative optimization of the patient, stratify their risk, maintain intraoperative hemostasis and treat postoperative bleeding complications in those patients who suffer them.

Key words:

POSTOPERATIVE BLEEDING

PROPHYLAXIS

MANAGEMENT

\section{Prevenção e gerenciamento de sangramento na cirurgia cardíaca}

\section{Resumo}

Todo procedimento cirúrgico envolve diferentes graus de agressão. A cirurgia cardíaca com o uso necessário da circulação extracorpórea impacta particularmente vários sistemas. Neste trabalho, será dada ênfase ao seu impacto na hemostase. O sangramento é uma das complicações mais comuns e mórbidas nesses pacientes. Embora mutifatorial na causa, a técnica cirúrgica, o tempo da circulação extracorpórea e as doenças pré-existentes tornam-se particularmente relevantes. $\mathrm{O}$

1. Instituto Nacional de Cirugía Cardíaca (INCC). Montevideo, Uruguay.

2. Centro Cardiovascular Universitario, Hospital de Clínicas. Montevideo, Uruguay.

Correspondencia: Dr. Fernando Delgado. Correo electrónico: delgadofernando33@gmail.com

Los autores declaran no tener conflictos de intereses.

Recibido Oct 2, 2020; aceptado Nov 6, 2020 
surgimento de novas drogas procoagulantes, novos sistemas de monitoramento de hemostase e o uso de protocolos de gestão com boas evidências mas baixa adesão até agora não conseguiram diminuir até agora o uso de hemocomponentes. Nesta revisão nós analisamos as recomendações atuais para o manejo do sangramento na cirurgia cardíaca, sua prevenção através da otimização pré-operatória do paciente, a estratificação do risco, o apoio da hemostase intraoperatória e o tratamento de complicações hemorrágicas pós-operatórias daqueles pacientes que os apresentam.

Palabras clave: $\quad$ SANGRAMENTO PÓS-OPERATÓRIO

PROFILAXIA

GESTÃO

\section{Introducción}

Durante largo tiempo se consideró que el corazón estaba fuera del ámbito accesible a la cirugía. En 1896 Stephen Paget escribió: "La cirugía cardíaca (CC) ha alcanzado los límites marcados por la naturaleza; ninguna nueva técnica o descubrimiento puede superar las dificultades naturales que ofrece reparar una afección cardíaca"(1). Sin embargo, los avances en este campo han sido continuos y extraordinarios, y el 20 de mayo de 1953 el doctor John $\mathrm{H}$. Gibbon Jr., realiza la primera CC (cierre septal auricular) con circulación extracorpórea (CEC)(2). Este logro técnico permitió resolver una diversidad de patologías que previamente implicaban una evolución inexorablemente adversa, pero también generó desafíos derivados de las profundas modificaciones fisiológicas que transitoriamente desencadena, entre las cuales se incluye la de la hemostasia.

En Uruguay se realizan aproximadamente $2.500 \mathrm{CC}$ por año ${ }^{(3)}$. El sangrado en el posoperatorio de estos pacientes no es infrecuente, y puede abarcar desde un sangrado insignificante que no requiere tratamiento específico, a una hemorragia severa con necesidad de implementar diversas estrategias. Se han desarrollado guías de manejo y protocolos para el pre, intra y posoperatorio, buscando mejorar el manejo de estos pacientes.

La presente revisión tiene como objetivo analizar los mecanismos subyacentes al sangrado y actualizar intervenciones destinadas a prevenir y tratar esta complicación. Se tratará el manejo rutinario en la evaluación de riesgos, prevención, monitorización de la hemostasis y tratamiento del sangrado en el paciente habitual, sin incluir el análisis de conductas y situaciones especiales que serán motivo de consideración futura (cirugía pediátrica, coagulopatías prexistentes, síndrome de Heyde, testigos de Jehová, etcétera).

\section{Manejo de la hemostasia}

Es necesario considerar: a) factores predictores de sangrado y requerimientos de hemoderivados en $\mathrm{CC}$; b) peculiaridades de la coagulopatía asociada a la CEC; c) sistemas de monitorización de la hemos- tasia disponibles; y d) propuestas de manejo de la hemorragia asociada a la CC y su reposición.

Para ello abordaremos cinco puntos:

1. Valoración preoperatoria del riesgo de sangrado.

2. Coagulopatía asociada a la CEC

3. Profilaxis del sangrado.

4. Sistemas de monitorización de la hemostasia en CC.

5. Terapéutica del sangrado.

\section{Valoración preoperatoria del riesgo de sangrado}

Se han identificado varios factores de riesgo de sangrado en el período preoperatorio (tabla 1).

Destacan los pacientes $>70$ años, con volumen sanguíneo reducido (baja superficie corporal, anemia o ambos), cirugías de emergencia o complejas (reintervenciones, cirugías no coronarias, cirugías sobre aorta, endocarditis).

Con respecto al tipo de cirugía y en orden descendente existe mayor riesgo en la patología de aorta ascendente, CC combinada (valvular y coronaria), valvular aislada y finalmente coronaria pura.

Tanto la identificación de estos factores como la implementación de medidas de conservación de sangre, la corrección de la anemia preoperatoria, el uso de fármacos antifibrinolíticos, recuperadores de sangre y algoritmos de transfusión guiados por monitorización de la hemostasia en block quirúrgico, tienen un nivel de evidencia A para mejorar la evolución y disminución del sangrado ${ }^{(4)}$.

\section{1.a Anemia preoperatoria}

Está asociada a mayor mortalidad perioperatoria y aumento de la probabilidad de transfusiones ${ }^{(5,6)}$. Se debe evitar llegar a cirugía con dosificaciones de hemoglobina $(\mathrm{Hb})<10 \mathrm{~g} / \mathrm{dl}$, que constituye un predictor de injuria renal, daño neurológico, sangrado y disfunción plaquetaria.

En la tercera parte de los pacientes anémicos $>65$ años, la principal etiología es el déficit fundamentalmente de hierro, pero también de vitamina $\mathrm{B}_{12}$ o folatos. Otro tercio es secundario a causas inflamatorias crónicas o enfermedad renal y el resto 


\begin{tabular}{lll}
$\begin{array}{l}\text { Tabla 1. Factores de riesgo asociados a sangrado o transfusión sanguínea durante o después de cirugía } \\
\text { cardíaca. Modificado de }{ }^{(4)} \text {. }\end{array}$ & \multicolumn{1}{c}{ Relativos al procedimiento } & \multicolumn{1}{c}{ Relativos al proceso } \\
\hline \multicolumn{1}{c}{ Relativos al paciente } & Tiempo de CEC prolongado & $\begin{array}{l}\text { Falta de algoritmos de transfusión } \\
\text { guiados por point of care test }\end{array}$ \\
\hline Edad > 70 años & Reintervención & Uso de arteria mamaria interna \\
Anemia preoperatoria & Tipo de cirugía & Bajas dosis de heparina \\
Sexo femenino & Altas dosis de protamina & Hipotermia en UCI \\
Terapia antitrombótica & Altas dosis de coloides & \\
Coagulopatía preoperatoria & Necesidad de transfusión en CEC & \\
Shock cardiogénico & Hemodilución normovolémica & \\
Insuficiencia cardíaca congestiva & intraoperatoria & \\
Baja fracción de eyección & & \\
Diabetes insulino requiriente & & \\
Vasculopatía periférica & & \\
Sepsis preoperatoria & & \\
Fallo hepático & & \\
\hline CEC: circulación extracorpórea; UCI: unidad de cuidados intensivos. &
\end{tabular}

\begin{tabular}{|c|c|c|c|c|}
\hline & Normal & Anemia crónica & Anemia ferropénica & $\begin{array}{c}\text { Anemia crónica }+ \\
\text { ferropénica }\end{array}$ \\
\hline FE sérico & $115 \pm 50$ & $\downarrow$ & $\downarrow$ & $\downarrow$ \\
\hline Transferrina & $28-360$ & $\mathrm{~N} \downarrow$ & $\uparrow$ & $\downarrow$ \\
\hline $\begin{array}{l}\text { Índice de saturación } \\
\text { de la transferrina }\end{array}$ & $33 \% \pm 15 \%$ & $\downarrow$ & $\downarrow \downarrow$ & \\
\hline Ferritina & $100 \pm 60$ & $\mathrm{~N} \downarrow$ & $\downarrow$ & $\mathrm{N} \downarrow$ \\
\hline Citoquinas & $\begin{array}{l}\text { VES }<15 \\
\mathrm{PCR}<5\end{array}$ & $\uparrow$ & $\mathrm{N}$ & $\mathrm{N} \uparrow$ \\
\hline Tipo de anemia & & $\begin{array}{l}\text { Normocítica } \\
\text { normocrómica }\end{array}$ & $\begin{array}{l}\text { Hipocrómica } \\
\text { microcítica }\end{array}$ & Microcítica \\
\hline Intensidad & & Ligera - moderada & Ligera - moderada & Moderada - grave \\
\hline Tratamiento & & $\begin{array}{c}\text { Eritropoyetina }+ \\
\text { ferroterapia }\end{array}$ & Ferroterapia & $\begin{array}{c}\text { Eritropoyetina }+ \\
\text { ferroterapia }\end{array}$ \\
\hline
\end{tabular}

es de causa desconocida. Investigar su causa y corregirla en la medida de lo posible antes de la cirugía debe ser nuestro objetivo.

Con niveles de $\mathrm{Hb}<12 \mathrm{~g} / \mathrm{dl}$ en mujeres y $13 \mathrm{~g} / \mathrm{dl}$ en hombres se considera útil analizar los parámetros hematimétricos, poniendo énfasis en el volumen corpuscular medio, metabolismo de hierro y en caso de necesidad, titular vitamina $\mathrm{B}_{12}$, ácido fólico y perfil inflamatorio (proteína $\mathrm{C}$ reactiva y VES).
Estos valores establecen un diagnóstico diferencial, permitiendo un tratamiento apropiado (tabla 2).

El tratamiento de la anemia ferropénica con hierro intravenoso es de elección sobre la vía oral en la población quirúrgica. Si bien el aporte de hierro se calcula mediante la fórmula de Ganzoni (Déficit total de hierro $=$ peso $[\mathrm{Kg}] \times \mathrm{Hb}$ deseada- $\mathrm{Hb}$ actual $(\mathrm{g} / \mathrm{dl}) \times 2,4+500)$, una infusión preoperatoria de hierro-sacarosa de $200 \mathrm{mg}$ cada $48 \mathrm{~h}$ hasta totalizar 


\begin{tabular}{|lcccc}
\hline \multicolumn{5}{l}{ Tabla 3. Principales propiedades de los antiagregantes plaquetarios. Modificado de ${ }^{(68)}$. } \\
\hline & Clopidogrel & Prasugrel & Ticagrelor & Cangrelor \\
\hline Mecanismo de acción & Irreversible & Irreversible & Irreversible & Reversible \\
Vía de administración & Oral & Oral & Oral & IV \\
$\%$ inhibición plaquetaria & $56 \%$ & $75 \%$ & $93 \%$ & $>90 \%$ \\
$\begin{array}{l}\text { Tiempo de normalización } \\
\text { de la función plaquetaria }\end{array}$ & 7 días & 7 días & $<5$ días & 60 min \\
$\begin{array}{l}\text { Tiempo de retirada antes } \\
\text { de la cirugía cardíaca }\end{array}$ & 5 días & 7 días & $3-5$ días & 1 a $6 \mathrm{~h}$ \\
\hline
\end{tabular}

$1000 \mathrm{mg}$ recupera la anemia en el $58 \%$ de los pacientes y puede aumentar la $\mathrm{Hb}$ en 1-2 g/dl. El compuesto hierro-carboximaltosa permite dar la dosis total del déficit calculado en una sola administración.

La anemia ferropénica se puede presentar aislada en pacientes con insuficiencia cardíaca congestiva (ICC) o asociada al síndrome cardiorrenal (anemia, ICC y enfermedad renal crónica [ERC]). En estos pacientes el tratamiento con eritropoyetina recombinante humana (EPO) puede mejorar la capacidad funcional, sin mayor mortalidad ni efectos ad$\operatorname{versos}^{(7)}$. Se considera razonable tratar con EPO y hierro una semana antes de la CC a los pacientes con anemia preoperatoria, los de alto riesgo de sangrado y los que rechazan los hemocomponentes (indicación clase IIa). Como contraindicaciones de EPO se incluyen cardiopatía isquémica inestable y arteriopatía grave ${ }^{(4)}$. El predepósito de sangre autóloga, si bien es posible en pacientes seleccionados, es difícilmente practicable, ya que se necesita una logística especial en los servicios de hemoterapia, con la cual no contamos en la actualidad.

\section{1.b Tratamiento antiagregante y anticoagulante}

La mayoría de los pacientes que requieren una cirugía coronaria están en tratamiento crónico con ácido acetilsalicílico (AAS). Los pacientes que cursan un síndrome coronario agudo (SCA) pueden estar recibiendo doble antiagregación (AAS y clopidogrel/prasugrel/ticagrelor). Aproximadamente un $10 \%-15 \%$ de éstos, requerirán cirugía de urgencia. Las guías actuales ${ }^{(8)}$ recomiendan:

- Todo paciente que tiene indicación de AAS, debe continuar recibiéndola hasta el día de la cirugía, salvo aquellos con riesgo de sangrado muy significativo (antecedentes heredo-familiares de coagulopatías, ERC, testigos de Jehová, cirróticos o que hayan recibido fibrinolíticos en los días previos) en los que se valora la suspensión cinco días antes.
- Suspender clopidogrel/prasugrel como mínimo cinco días antes; óptimo siete días.

- Cirugía de urgencia o emergencia en pacientes portadores de stents farmacoactivos implantados seis meses antes (o seis semanas en los convencionales) no suspender la doble antiagregación, asumiendo un mayor riesgo de sangrado ${ }^{(9)}$.

En la tabla 3 se muestran las características de los antiagregantes de uso habitual.

Inhibidores de la glucoproteína IIb IIla

Con el uso de tirofiban el $90 \%$ de la función plaquetaria se recupera a las 4-8 h; debe suspenderse por lo menos $4 \mathrm{~h}$ pre CC. Con respecto al eptifibatide, se recupera entre el 50\%-80\% de la función plaquetaria tras las 4 h de suspensión. El abciximab, con una vida media de más de $12 \mathrm{~h}$, obligaría a retrasar la cirugía al menos $48 \mathrm{~h}$.

Respecto al tratamiento anticoagulante oral, tiene especial interés el manejo de los fármacos antivitamina $\mathrm{K}$ en situaciones de urgencia. Se debe suspender el medicamento y administrar vitamina K 5-10 mg IV. En caso de emergencia, (trasplante cardíaco, disección de aorta) se requiere reposición con plasma fresco congelado y/o complejo protrombínico (indicación clase I, nivel de evidencia C) ${ }^{(10)} \mathrm{La}$ dosis única de complejo protrombínico se administra si INR >3, $30 \mathrm{U} / \mathrm{kg}$; y si INR <3, $10 \mathrm{U} / \mathrm{kg}$. Los anticoagulantes orales directos deben suspenderse al menos $48 \mathrm{~h}$ antes de la cirugía (tabla 4). Respecto a los test básicos de la coagulación: dabigatrán altera el tiempo de trombina, mientras que rivaroxabán, apixabán y todos los compuestos anti-X, pueden alterar el tiempo de protrombina. La determinación de su concentración plasmática (no disponible en nuestro medio) permite realizar la cirugía cuando es $<30 \mathrm{ng} / \mathrm{ml}$, y sería necesario posponerla $12 \mathrm{~h}$ frente a concentraciones de $30-200 \mathrm{ng} / \mathrm{ml}$ y $24 \mathrm{~h}$ entre $200-400 \mathrm{ng} / \mathrm{ml}$.

En caso de recibir heparina de bajo peso molecular (HBPM) se aconseja su suspensión entre 18-24 h 


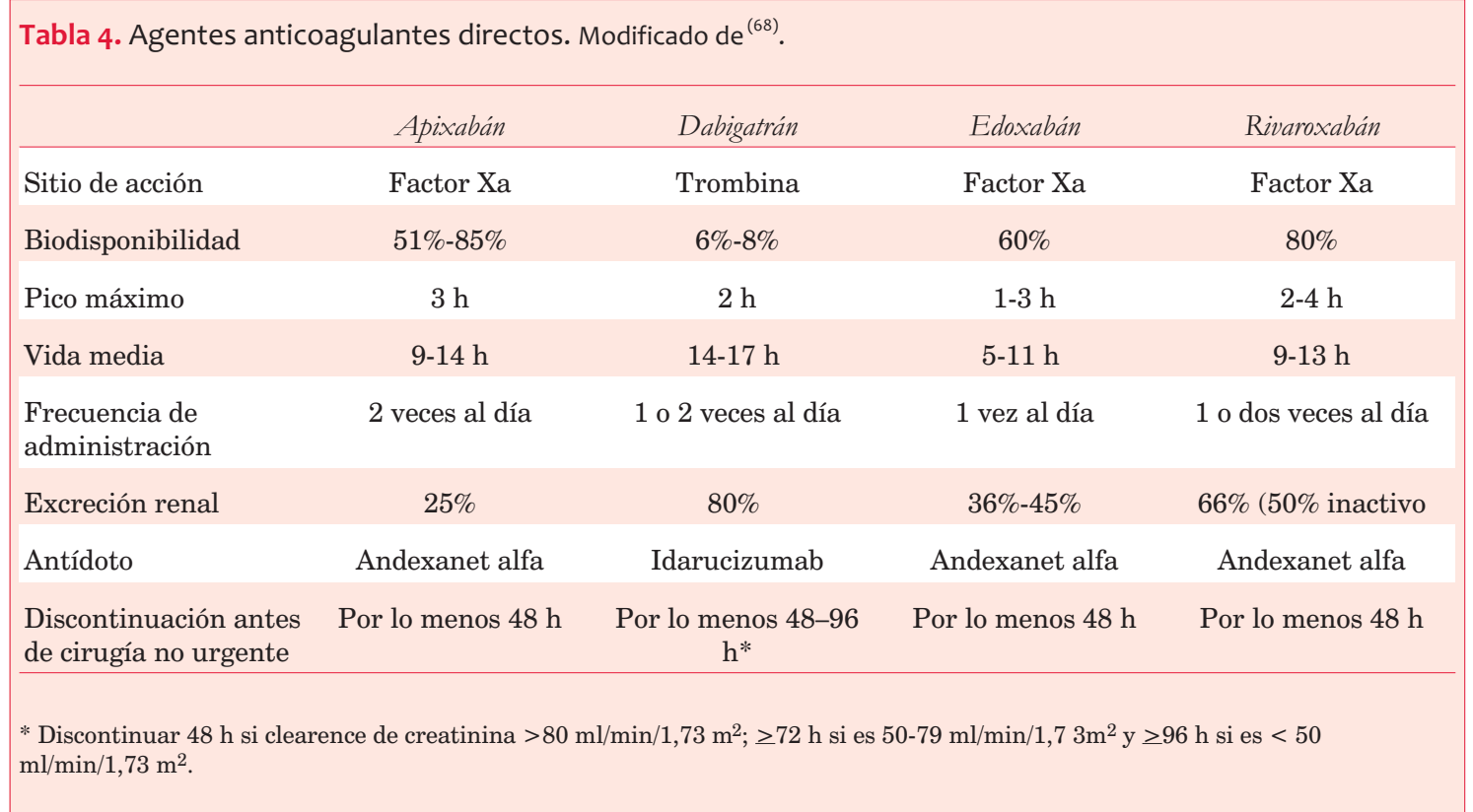

antes de la CC. Con la heparina no fraccionada (HNF) 4 h es suficiente, si bien en pacientes de riesgo isquémico elevado se puede mantener hasta la llegada a block.

\section{Hemostasia y coagulopatía asociada a la circulación extracorpórea}

La CEC experimentó desde 1953 hasta la fecha un notable avance gracias al cual hoy se pueden realizar prácticamente todos los procedimientos quirúrgicos sobre el corazón. Tiene como finalidad perfundir y proteger los órganos, manteniendo un aporte de sangre y oxígeno a los tejidos durante el periodo de reparación quirúrgica donde es necesario remplazar parcial o totalmente las funciones cardíaca y pulmonar en forma temporaria. Como contrapartida, es profundamente antifisiológica por los siguientes cambios:

1. La sangre entra en contacto con superficies extrañas al endotelio.

2. Se excluyen los pulmones y el corazón del circuito, con lo cual se eliminan las funciones metabólicas y de filtro, y se compromete su autorregulación.

3. Cambio de flujo pulsátil a flujo continuo.

4. Cambios agudos de temperatura (normotermia, hipotermia).

5. Hemodilución.

6. Uso de anticoagulantes sistémicos y su reversión.

Todas estas modificaciones llevan a que el paciente bajo CEC se someta a riesgos y complicaciones como embolias, trastornos de la coagulación, alteraciones de la inmunidad, activación del sistema de respuesta inflamatoria y respuesta neuroendócrina $^{(11)}$. Los trastornos de la hemostasia se producen a todos los niveles, pero los más relevantes son sobre las plaquetas, las cuales disminuyen durante la CEC en cantidad por destrucción, hemodilución, secuestro, y en su capacidad funcional.

El circuito de CEC necesita ser cebado con soluciones electrolíticas para evitar embolia aérea. El volumen de este cebado es generalmente $30 \%$ el de la volemia de un adulto.

Una hemodilución leve reduce la viscosidad de la sangre e incrementa el flujo cerebral. Sin embargo hemodiluciones moderadas a severas pueden resultar en disminución de transporte de oxígeno e isquemia tisular. El valor de hematocrito aceptable varía entre $18 \%-30 \%$, dependiendo de la edad, comorbilidades y tipo de procedimiento. Los daños potenciales de la hemodilución han sido exhaustivamente estudiados ${ }^{(12,48)}$, con evidencia de que un valor medio por debajo de $25 \%$ se asocia a mayor morbilidad. Existen diversas estrategias para el manejo de la anemia intraoperatoria (figura 1).

En conclusión: una anemia moderada con hematocrito entre $21 \%$ - $25 \%$ es generalmente bien tolerada en la mayoría de los pacientes sometidos a CC con CEC, mientras que la anemia severa por hemodilución puede asociarse con daño orgánico, particularmente en los pacientes añosos.

La disminución del número de plaquetas secundaria a la hemodilución asociada a la CEC suele ser del 30\%-50\%. La trombina, la plasmina, el ADP liberado por los hematíes dañados en la CEC y la heparina, son potentes estímulos para la activación plaquetaria. La hipotermia contribuye a la disfunción, dado 


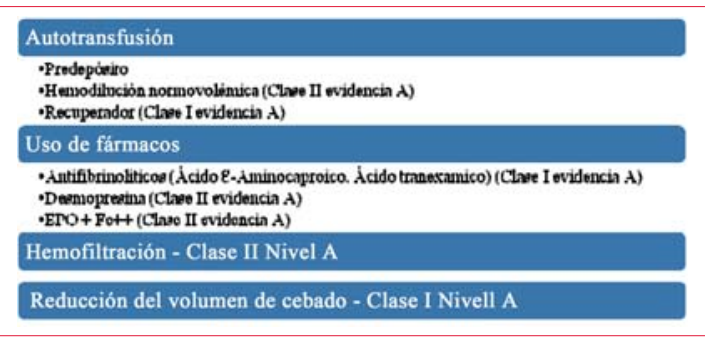

Figura 1. Estrategias para disminuir la anemia intraoperatoria. Modificado de ${ }^{(24)}$. EPO: eritropoyetina; Fe: hierro

que enlentece la actividad enzimática de la coagulación, disminuye la síntesis de factores, altera la función plaquetaria e induce fibrinólisis ${ }^{(13,14)}$.

La trombocitopenia y la disfunción plaquetaria se consideran la principal anormalidad responsable del sangrado luego de $\mathrm{CC}$ con $\mathrm{CEC}^{(15,16,17)}$. Tradicionalmente se consideraba la activación de la coagulación a través de los factores de contacto, pero también se estimula la formación de trombina por la generación y activación de mediadores inflamatorios que favorecen la expresión sistémica del factor tisu$\operatorname{lar}^{(18)}$. Todas estas alteraciones son dependientes del tiempo de CEC: a mayor duración, mayor disfunción ${ }^{(19)}$. Una vez realizada la corrección quirúrgica y finalizada la CEC, debe neutralizarse la actividad de la heparina mediante la utilización de sulfato de protamina.

Esta reversión no está exenta de riesgos; puede producir reacciones que van desde hipotensión leve, disminución del inotropismo y liberación de histamina, hasta una vasoconstricción pulmonar severa con riesgo vital, efectos poco frecuentes y relacionados con la exposición previa y con la velocidad de administración del fármaco ${ }^{(20)}$.

La respuesta inflamatoria es el resultado de la actuación sinérgica de los tres grandes sistemas humorales de protección del organismo: sistema de coagulación (factor XII de Hageman), sistema de las cininas y sistema de activación del complemento. Esta respuesta es autolimitada y tiende a normalizarse en las primeras $12-24 \mathrm{~h}$ del posoperatorio, dependiendo del tiempo de clampeo aórtico, de CEC y del tipo de cirugía. Se pueden evidenciar dos fases, una inicial proinflamatoria con incremento en la actividad celular (leucocitosis de todas sus líneas celulares) con la consecuente degranulación y posterior disminución en la actividad de estas células. Esta fase está en íntima relación con el contacto de la sangre con superficies extrañas, activación del sistema del complemento, el sistema de calicreínas-fibrinólisis y el sistema de la coagulación. Se genera una respuesta difusa con elevación marcada del complemento, principalmente las anafilotoxinas C3a y C5a ${ }^{(21)}$, lo cual lleva a activación, migración y degranulación de los polimorfonucleares

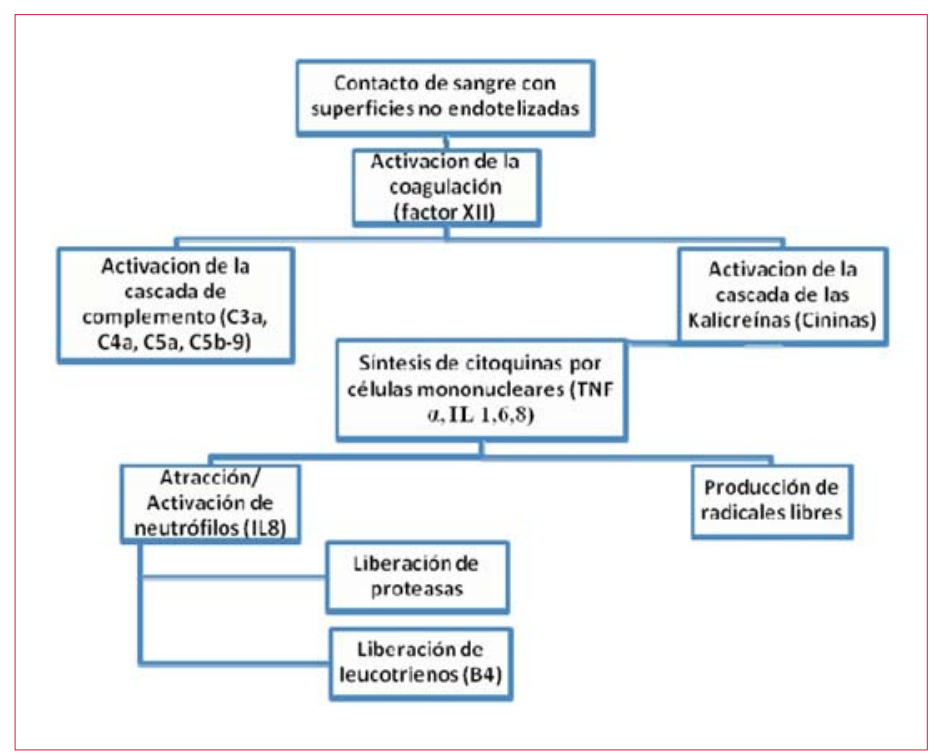

Figura 2. Mecanismo básico de la respuesta inflamatoria sistémica. Modificado de ${ }^{(25)}$. TNF: factor de necrosis tumoral; IL: interleuquina.

(PMN), activación de linfocitos T y B, y producción de interleukinas (IL) (22), específicamente IL 1, IL 6 e IL $8^{(19)}$. Es de destacar que los niveles pico de IL 6 se correlacionan con el grado de disfunción miocárdica y con el tiempo de clampeo ${ }^{(23)}$. Durante esta fase se observan las secuelas pulmonares que van desde hipoxemia leve hasta distrés respiratorio severo, síndrome de fuga capilar con incremento de la permeabilidad, lesión plaquetaria, hemólisis y fibrinólisis.

La segunda es la fase anérgica, donde hay una disminución de la respuesta inmunológica tanto humoral como celular. Las causas de la disminución de la inmunidad humoral (hemodilución, formación de macroagregados, disminución de la producción de anticuerpos, consumo en el oxigenador, desnaturalización de proteínas y migración intersticial por alteración de la permeabilidad capilar), llevan a una reducción de la actividad bactericida con descenso de la concentración de inmunoglobulinas, complemento y capacidad de opsonización ${ }^{(22)}$. La inmunidad celular se ve afectada por disfunción de los PMN, macrófagos y linfocitos tanto de la línea T como B, con la consecuente disminución fagocítica ${ }^{(11)}$. Esto aumenta el riesgo de infecciones, pues por un lado, se han roto las barreras naturales de protección (monitorización hemodinámica invasiva, sonda vesical, incisión quirúrgica, vía aérea) y por otro lado, se ha reducido la capacidad de respuesta. De un adecuado balance entre estas dos fases dependerá la recuperación o el daño de órganos. Es de resaltar que estas fases también se pueden encontrar en la cirugía sin CEC, aunque la respuesta inflamatoria es menor ${ }^{(22)}$, con menos producción de IL (figura 2). 


\section{Profilaxis del sangrado}

\section{3. a Evitar el consumo de factores}

Iniciar y mantener la anticoagulación durante la CEC es fundamental para proteger los factores y evitar la formación de trombos dentro del circuito extracorpóreo. En condiciones usuales sólo los factores II, V, VII y X disminuyen. La HNF es el fármaco de elección, debido a su rápido inicio de acción y por contar con un agente neutralizante. Se une con gran afinidad a la antitrombina III y potencia aproximadamente 1.000 veces su actividad. Las dosis recomendadas son $2-4 \mathrm{mg} / \mathrm{kg}$ (10 mg=1.000 UI) para alcanzar un tiempo de coagulación activado (TCA) $\geq 480$ s. Existen sistemas sofisticados que permiten monitorizar la concentración de heparina circulante durante la CEC. La neutralización con sulfato de protamina se realiza con un ratio de 0,8-1,3 a 1 . Se ha definido la resistencia a la heparina como la falta de respuesta adecuada después de una dosis estándar, aunque sin un adecuado consenso, por lo que sobre su frecuencia existe una variabilidad en la literatura entre 5\%-60\% de los pacientes interveni$\operatorname{dos}^{(26)}$. La HNF es casi exclusivamente utilizada para anticoagulación en CEC, pero el paciente expuesto anteriormente a heparina tiene riesgo de desarrollar anticuerpos contra el complejo heparina-factor 4 plaquetario (heparina-PF4). La administración de heparina en presencia de estos anticuerpos anti heparina-PF4 puede resultar en trombocitopenia inducida por heparina (TIH) o en una complicación más grave: el síndrome de trombosis y trombocitopenia inducida por heparina. En estos pacientes, de muy alto riesgo, existen alternativas al uso de heparina ${ }^{(27)}$. En nuestro medio no se han reportado dificultades para el mantenimiento de la anticoagulación en CEC.

Se deben considerar especialmente los pacientes $>65$ años, los portadores de trombocitosis, el uso preoperatorio de heparina y el déficit de antitrombina conocido. En caso de que el TCA con la dosis estándar no llegue a $300 \mathrm{~s}$, en un paciente adulto se administran dos unidades de plasma fresco (con lo que se asegura el aporte de antitrombina III), se controla nuevamente el TCA y se procede a la entrada en CEC. Si bien las guías estadounidenses recomiendan la administración de concentrado de antitrombina, no se dispone en nuestro país de antitrombina comercial ${ }^{(4)}$.

\section{3.b Controlar la fibrinólisis}

La hiperfibrinólisis se desencadena por la activación de la coagulación al entrar en contacto la sangre con el circuito, por el activador tisular del plasminógeno inducido por niveles altos de bradicinina y por disminución de su inhibición; nuevamente aquí la hipotermia juega su rol favorecedor ${ }^{(28)}$. Tanto las guías europeas como estadounidenses ${ }^{(4,29)}$ hacen una indicación IA de los fármacos antifibrinolíticos como profilácticos para disminuir el sangrado, las transfusiones y la necesidad de reintervención en pacientes de $\mathrm{CC}$.

Existen dos tipos de fármacos: a) inhibidores directos del plasminógeno: los análogos de la lisina, como el ácido tranexámico (Transamina®) y el ácido épsilon-amino-caproico (EACA) (Ipsilon $\left.{ }^{\circledR}\right)$; y b) los inhibidores de la serinproteasa: aprotinina ${ }^{(30-32)}$. El ácido tranexámico es entre 5-10 veces más potente que EACA y tiene una vida media más larga. La aprotinina es un polipéptido extraído del pulmón bovino; inhibe tripsina, quimotripsina, plasmina, trombina y calicreína a través de la formación de complejos reversibles inhibidos por enzimas ${ }^{(33)}$.

En mayo de 2008 la FDA suspendió la licencia de la aprotinina en Estados Unidos, por lo que además se discontinuó su producción. Esto fue debido al resultado del estudio BART, que mostró aumento significativo de la mortalidad entre los pacientes que la recibieron ${ }^{(34)}$. Sin embargo, por su mayor potenciay sus propiedades antiinflamatorias, persiste el interés por este fármaco, y hay autores que sugieren que el perfil riesgo-beneficio en pacientes de alto riesgo es favorable ${ }^{(35,36)}$. Actualmente ha sido reaprobada en países europeos y en Canadá. Todavía no está disponible en Estados Unidos ni en nuestro medio.

La seguridad de los análogos de la lisina está menos estudiada. En Uruguay es más usada la transamina con respecto a EACA; su vida media es de 80 min, y se elimina en un $95 \%$ por vía renal. La principal complicación en el posoperatorio temprano son las convulsiones, y están relacionadas con dosis $>100 \mathrm{mg} / \mathrm{kg}$. Existen varios protocolos, desde 50 $\mathrm{mg} / \mathrm{kg}$ previo a la incisión de la piel y similar dosis luego de la reversión de heparina a la salida de CEC, hasta una dosis de $12,5 \mathrm{mg} / \mathrm{kg}$ seguida de infusión continua de $6,5 \mathrm{mg} / \mathrm{kg} / \mathrm{hora}+1 \mathrm{mg} / \mathrm{kg}$ en el cebado de CEC, que según estudios farmacocinéticos proporciona una concentración plasmática de $345 \mathrm{mi}$ cromoles/min, teniendo en cuenta la función renal.

Con respecto al EACA se realiza dosis carga en la inducción anestésica 1-15 g, manteniendo 1-2 g/h durante la cirugía. El efecto adverso más importante es la nefrotoxicidad.

\section{Monitorización de la hemostasia peroperatoria}

A pesar de los avances en los sistemas de monitorización de la hemostasia, estos no son buenos predictores de sangrado ${ }^{(37)}$. Es razonable que en el pacien- 
te "sangrante", un rápido y preciso diagnóstico de las causas del sangrado oriente la indicación del tratamiento más eficaz y reduzca las necesidades de transfusión y el número de reintervenciones por sangrado.

Las pruebas de laboratorio tienen sus limitaciones:

a. Tiempo de proceso (30-45 $\mathrm{min})$.

b. Recuento plaquetario: informa número pero no función.

c. El tiempo de protrombina y KPTT se realizan en plasma, detectan déficit de los factores pero no la interacción que in vivo tienen esos componentes plasmáticos con los celulares, finalizan con la producción de trombina antes de que la fibrina sea polimerizada por el factor XIIIa y de que el fibrinógeno establezca puentes entre las plaquetas a través de los receptores GPIIb-IIIa.

d. No aporta pruebas para detectar estados de hiperfibrinólisis.

e. En la determinación del fibrinógeno (método de Clauss) si se utiliza el método óptico puede estar sobrestimado por los productos de degradación de fibrinógeno, pigmentos biliares, $\mathrm{Hb}$ libre o elevada concentración lipídica, no así cuando se utiliza el método mecánico.

Para sortear algunas de estas limitaciones contamos con los sistemas de monitorización en la cabecera del paciente (point of care tests):

- TCA: permite monitorizar la anticoagulación con heparina durante la CEC utilizando celite o caolín para acelerar el proceso, activando la vía de contacto. Tiene dos propósitos: a) asegurar la dosis de heparina necesaria para suprimir la actividad de la trombina; y b) detectar si hay heparina residual posterior a su neutralización con protamina. El valor del TCA se correlaciona linealmente con la concentración de heparina y los protocolos son de 3-4 mg/kg para conseguir un TCA entre 400-480 s. La respuesta a la heparina varía de un paciente a otro; tampoco hay un valor de TCA óptimo para mantener la anticoagulación adecuada durante la CEC. Hay condiciones que lo prolongan: hipotermia, hemodilución, trombocitopenia y trombocitopatías ${ }^{(38)}$.

- Tromboelastografia (TEG) y tromboelastometría (ROTEM): utilizan tests dinámicos para evaluar las características del coágulo, basándose en la medición de la viscoelasticidad de una muestra de sangre entera después de activar la coagulación con un reactivo específico ${ }^{(39)}$. Analizan el cambio en las propiedades viscoelásticas durante la formación y lisis del coágulo. Según los reactivos utilizados se obtienen diferen- tes tests que en 10-20 min informan la presencia o ausencia de coagulopatía y de su causa. Permiten detectar los efectos de la hemodilución sobre la firmeza del coágulo y la disfunción plaquetaria no secundaria a fármacos ${ }^{(40)}$. Son el patrón de referencia en el diagnóstico de la hiperfibrinólisis, con un alto valor predictivo negativo(41). Si bien son point of care tests y hay reactivos que permiten realizar pruebas durante la CEC, también es cierto que existen limitaciones técnicas y curvas de aprendizaje ${ }^{(42)}$. Desde hace varios años existe bibliografía que avala la introducción de esta monitorización y su combinación con algoritmos transfusionales en el manejo del sangrado peroperatorio de CC para reducir la tasa de transfusiones, resultando costo-efecti$\mathrm{va}^{(43-45)}$. El sistema ROTEM ha presentado un nuevo módulo que se puede incorporar al dispositivo y permite además el análisis simultáneo de la agregación plaquetaria utilizando agregometría de impedancia ${ }^{(46)}$.

\section{Objetivos terapéuticos en el sangrado masivo}

En los pacientes sometidos a CC el sangrado es un evento común. Aproximadamente 10\% de ellos presentan sangrado severo y cerca de $5 \%$ requieren reintervención ${ }^{(47,48)}$.

Hay evidencia de que tener menor sangrado mejora los resultados y evita transfusiones, lo que se asocia con disminución en la morbilidad posoperatoria, incluyendo menos infecciones, fibrilación auricular, complicaciones respiratorias, injuria renal aguda y disminución de mortalidad a corto y largo $\operatorname{plazo}^{(49,50)}$.

El sangrado es, por tanto, un importante indicador de resultado en estudios randomizados, pero a diferencia de otras complicaciones, como injuria renal, infarto de miocardio o eventos neurológicos, no existe una definición estandarizada de sangrado posoperatorio, lo que dificulta la interpretación y posterior tratamiento. Es por tanto importante tener una definición más precisa de entidad de sangrado.

\section{5.a Definición de sangrado excesivo en el peroperatorio de cirugía cardíaca}

En 2014 se propuso por un comité de expertos ${ }^{(47)}$ el uso de una definición universal de sangrado perioperatorio en CC de adulto para estandarizar la nomenclatura, mejorar las definiciones y ayudar en trabajos futuros. Usando solo parámetros clínicos relevantes, se crea un sistema de cinco clases que puede ser aplicado tanto en la práctica diaria como en investigaciones clínicas. Es un instrumento en la mejora de la calidad, y una herramienta útil para proponer, evaluar e implementar soluciones adap- 


\begin{tabular}{|c|c|c|c|c|c|c|c|c|c|}
\hline $\begin{array}{l}\text { Definición de } \\
\text { sangrado }\end{array}$ & $\begin{array}{c}\text { Cierre esternal } \\
\text { retrasado }\end{array}$ & $\begin{array}{l}\text { Pérdida por el } \\
\text { drenaje dentro } \\
\text { de las } 12 \mathrm{~b}(\mathrm{ml})\end{array}$ & $\begin{array}{l}\text { Unidaddes } \\
\text { sangre } \\
\text { desplasmat. }\end{array}$ & $\begin{array}{l}\text { Unidad de } \\
\text { plasma fresco }\end{array}$ & $\begin{array}{l}\text { Unidad de } \\
\text { plaquetas }\end{array}$ & $\begin{array}{l}\text { Crioprecipi- } \\
\text { tados }\end{array}$ & $\begin{array}{c}\text { Complejo } \\
\text { protrombinico }\end{array}$ & $\begin{array}{r}\text { Factor } \\
\text { VIIa }\end{array}$ & $\begin{array}{l}\text { Reexploración } \\
\text { / taponamiento }\end{array}$ \\
\hline 0 insignificante & No & $<600$ & 0 & 0 & 0 & No & No & No & No \\
\hline 1 leve & No & $601-800$ & 1 & 0 & 0 & No & No & No & No \\
\hline 2 moderado & No & $801-1.000$ & $2-4$ & $2-4$ & Sí & Sí & Sí & No & No \\
\hline 3 severo & Sí & $1.001-2.000$ & $5-10$ & $5-10$ & - & - & - & No & Sí \\
\hline 4 masivo & - & $>2.000$ & $>10$ & - & - & - & - & $\mathrm{Si}$ & - \\
\hline
\end{tabular}

tadas a cada centro, para reducir el sangrado y las necesidades de transfusión. Está basado en siete eventos que ocurren en la cirugía o en el primer día de posoperatorio (tabla 5).

1. Cierre esternal retrasado. Identifica a aquellos pacientes con sangrado intraoperatorio severo y refractario, que abandonan el block quirúrgico con packing de compresas como coadyuvante hemostático.

2. Gasto por el tubo de drenaje. Usado de rutina en la práctica clínica, ha sido adoptado como medida en trabajos de investigación, con sus limitaciones. Se inicia con el cierre esternal y se contabiliza durante las primeras $12 \mathrm{~h}$, ya que refleja eventos tempranos y excluye la etapa intraoperatoria.

3. Transfusión de hemocomponentes. Si bien no mide directamente el sangrado y hay amplia variabilidad en las indicaciones de transfusiones, existe relación con la magnitud del sangrado. Se contabilizan las transfusiones que se realizan después del cierre esternal. El mismo criterio se utiliza para el uso de plaquetas, plasma fresco congelado y crioprecipitados.

4. Uso de crioprecipitados. Al ser el fibrinógeno el primer factor en consumirse durante la activación de la coagulación y si bien su disponibilidad y uso varía en diferentes regiones, es un marcador relevante de sangrado significativo.

5. Uso de concentrado de factores. Complejo protrombínico y fibrinógeno comercial. Si es necesario su uso, por lo menos se trata de un sangrado moderado o clase 2 .

6. Uso de factor VIIa. Indicado en sangrado refractario que pone en riesgo la vida. Sabemos que en principio debe ser evitado por el riesgo de complicaciones tromboembólicas, limitando su uso a situaciones en las que otras opciones terapéuticas han fallado(51).

7. Reintervención. Técnica de rescate común cuando no se logra contener el sangrado, aunque no inocua ni exenta de efectos adversos. Es,
Tabla 6. Criterios de sangrado excesivo según hora transcurrida desde la cirugía

\begin{tabular}{lc}
\hline $1^{\text {a }}$ hora & $>500 \mathrm{ml} \mathrm{o}>5 \mathrm{ml} / \mathrm{kg} /$ peso \\
$2^{\text {a }}$ hora & $>400 \mathrm{ml}$ \\
$3^{\text {a }}$ hora & $>300 \mathrm{ml}$ \\
$4^{\text {a hora }}$ & $>200 \mathrm{ml}$ \\
$5^{\text {a hora }}$ & $>100 \mathrm{ml}$ \\
\hline
\end{tabular}

por sí misma, una medida de que el sangrado es severo $^{(52)}$ (tabla 5). Puede ocurrir en forma precoz o tardía, y es un indicador de calidad del procedimiento quirúrgico ${ }^{(35,53,54)}$.

Esta clasificación ha probado su eficacia como herramienta descriptiva y en la predicción de resultados clínicos. La clase de sangrado (0-4) se asocia a diferentes porcentajes de mortalidad. En dos tercios de los pacientes cursando un posoperatorio CC es insignificante o leve, con baja mortalidad, sin diferencia en la mortalidad entre sangrado insignificante y leve. El sangrado moderado sí tiene un incremento en la mortalidad, mayor aún en las categorías de sangrado severo y masivo. Por lo tanto, los esfuerzos para transformar un porcentaje de pacientes de sangrado moderado a insignificante $o$ leve son de beneficio. Los efectos sobre la estadía en terapia intensiva o el tiempo de extubación de los pacientes merecen más estudios.

La evolución en las primeras $24 \mathrm{~h}$ del posoperatorio es crucial desde el punto de vista del sangrado, tomando importancia el ritmo en las primeras horas, que pasa a ser uno de los indicadores clave para la reintervención, ya que cuanto más prolongado es el sangrado, más se agrava una potencial o manifiesta coagulopatía.

Si bien según los autores hay varias reglas a seguir para catalogar un sangrado excesivo, pueden considerarse los criterios mencionados en la tabla 6 . 
Tabla 7. Intervenciones intra y posoperatorias para evitar el sangrado excesivo en cirugía cardíaca. Modificado de ${ }^{(68)}$.

$\begin{array}{ll}\text { Intraoperatorias } & \text { Posoperatorias }\end{array}$

Mantenimiento de la hemostasis y disminuir el sangrado

Hemostasis quirúrgica

meticulosa

Minimizar hemodilución (por

ejemplo cebado CEC)

Valoración individual de dosis

de heparina y protamina

Normotermia $\left(>36^{\circ} \mathrm{C}\right)$ y

normalización de $\mathrm{pH}(7,35-7,45)$ Mantenimiento de la perfusión tisular
tisu de la p

Prevención de fibrinólisis

Acido tranexámico, Ácido épsilon-amino- caproico, aprotinina.

Minicircuito EC, priming anterógrado o retrógrado

Medición de TCA, heparina o Factor Xa.

Calentamiento del paciente.

Tratamiento del sangrado microvascular luego de CEC

Algoritmos perioperatorios para Test de laboratorio o point of los pacientes sangrantes care test

Niveles bajos de fibrinógeno $(<1,5 \mathrm{~g} / \mathrm{l})$ o firmeza del coágulo disminuida

Deficiencia de factores de coagulación (tiempos de coagulación prolongados)

Bajos recuentos plaquetarios (<50 × $10^{9} / 1$ y/o terapia antiplaquetaria

Anemia
Concentrado de fibrinógeno

Plasma fresco o complejo protrombínico

Transfusión de plaquetas o desmopresina

Transfusión de sangre Desplasmatizada basada en condiciones individuales

Uso de recuperador celular

EC: extracorpóreo; TCA: tiempo de coagulación activado; CEC: Circulación extracorpórea.

De acuerdo a esta cuantía hay que valorar la posibilidad de reexploración, así como si hay sospecha clínica aunque el gasto por los drenajes sea escaso. Esta sospecha clínica debe plantearse ante un paciente con taquicardia, hipotensión, aumento de la presión venosa central, cese abrupto del gasto por los drenajes, alteraciones en los tests de hemostasis que no mejoran y acidosis persistente, lo que conduce a una deuda de oxígeno y shock. Como corolario, la necesidad de reexploración no la decide aisladamente ningún estudio de coagulación, ni tampoco si se trata de un sangrado médico o quirúrgico.

\section{5.b Detener la hemorragia}

Confirmar o descartar coagulopatía para decidir reintervenir o indicar el producto sanguíneo a transfundir.

\section{5.c Mantener la perfusión y la oxigenación tisular}

Restaurar el volumen sanguíneo con cristaloides isotónicos y suero salino hipertónico, teniendo la precaución de no incrementar la coagulopatía por hemodilución. Considerar el uso de hipotensión permisiva (PAM $50 \mathrm{mmHg}$ ). Contemplar el uso de vasoconstrictores para mantener la presión arterial después de la administración de fluidos. Mantener la oxigenación tisular con niveles de $\mathrm{Hb}$ entre 7-9 $\mathrm{g} / \mathrm{dl}$ mediante la administración de sangre desplasmatizada.

\section{5.d Uso de fármacos en forma empírica}

Desmopresina en dosis de $3 \mu \mathrm{g} / \mathrm{kg}$. Solo tiene indicación profiláctica en pacientes con enfermedad renal crónica y en la enfermedad de Von Willebrand (indicación IIa). Se puede repetir a las $2 \mathrm{~h}$.

\section{5.e Corregir la coagulopatía}

Reponer factores de la coagulación y plaquetas con el uso racional de componentes sanguíneos y fármacos pro hemostáticos.

Sangre desplasmatizada. Es una indicación I evidencia $B$ transfundir en base a las condiciones clínicas del paciente en vez de utilizar un nivel fijo de hemoglobina ${ }^{(55,56)}$. Las guías más recientes (EACTS y EACTA) proponen reponer con niveles $\leq 7,5 \mathrm{~g} / \mathrm{dl}$, lo cual es clínicamente razonable, práctico y aceptado en la mayoría de los centros. Hay evidencia de que la fecha de caducidad de la sangre transfundida no afecta la mortalidad, los eventos adversos ni las infecciones nosocomiales ${ }^{(57-59)}$.

La leucorreducción de la sangre desplasmatizada es un procedimiento estándar en Europa, no así en Latinoamérica. Si bien no hay diferencias en mortalidad, existe indicación I evidencia B para reducir las complicaciones infecciosas. Se asume que los monocitos alogénicos son la causa de la inmunomodulación, así como péptidos antigénicos leucocitarios y mediadores solubles que se transfunden sobre todo con la sangre desplasmatizada ${ }^{(60)}$. La inmunomodulación se ha asociado a aumento de mor- 
bimortalidad en CC y a un aumento del riesgo de infecciones ${ }^{(61,62)}$.

En nuestro país en la mayoría de los centros la desleucotización se realiza en el momento de la transfusión y no todas las unidades se transfunden desleucotizadas, ya que su uso estaría indicado además en pacientes que presenten reacciones de escalofrío-hipertermia por anticuerpos antileucocitarios; en prevención de la aloinmunización por anticuerpos leucoplaquetarios y como alternativa a productos citomegalovirus negativos. Las transfusiones de sangre recuperada del campo operatorio son recomendadas y están asociadas con disminución de la anemia y menos unidades de sangre transfundidas, así como menor riesgo de complicaciones pulmonares posoperatorias ${ }^{(63)}$.

Concentrados plaquetarios (de pool de donantes o de donante único). No hay estudios concluyentes que muestren a un valor de recuento plaquetario o un estudio funcional que identifique el umbral para indicar su reposición ni que ésta sea la principal estrategia para disminuir o detener el sangrado microvascular. A pesar de ello, un recuento $<50.000 / \mathrm{mm}^{3}$ es un valor recomendado luego de la neutralización de la protamina, y de preferencia luego del cierre del esternón (indicación IIa evidencia C) ${ }^{(64)}$. Si hay antecedentes de consumo de antiagregantes plaquetarios (inhibidores $\mathrm{P} \mathrm{Y}_{12}$ ), los tests de función plaquetaria no están disponibles en la urgencia.

En este caso se administra desmopresina en dosis de $0,3 \mu \mathrm{g} / \mathrm{kg}$ en $100 \mathrm{ml}$ de suero fisiológico en 30 minutos. Para el ticagrelor administrado en las $12 \mathrm{~h}$ previas, la transfusión de plaquetas es inefecti$\mathrm{va}^{(65,66)}$. En otros medios existe el CytoSorb ${ }^{\circledR}$, dispositivo que absorbe el ticagrelor y el rivaroxaban; se acopla al circuito de CEC.

Plasma fresco congelado. No hay evidencia para el uso de este hemocomponente en forma preventi$\mathrm{va}^{(67)}$. En las últimas guías especializadas existe una tendencia a recomendar el uso de complejo protrombínico para la corrección de los factores específicos de la coagulación diagnosticados por point of care test o por el laboratorio en pacientes sangrantes en lugar de plasma fresco ${ }^{(68)}$. No existe evidencia de que su uso profiláctico o terapéutico disminuya el sangrado en el posoperatorio de CC. Como conlleva los efectos secundarios de los hemocomponentes es una indicación IIb; puede ser usado en caso de sangrado posoperatorio ${ }^{(67-69)}$. Su uso es adecuado cuando está aumentado el tiempo de protrombina. También con KPTT prolongado, lo que está indicando un problema en el componente intrínseco de la coagulación o persistencia de heparina circulante.

Crioprecipitados. Actualmente no están disponibles en la mayoría de los países europeos. En Uruguay, si bien ha disminuido su producción ya que los principales requirientes son los pacientes hemofílicos y se tratan con factor VIII o IX comercial, aún existe disponibilidad en los servicios de hemoterapia. Puede ser usado a una dosis de 1 Unidad cada $10 \mathrm{~kg}$ de peso. Su indicación es el déficit de fibrinógeno. Como dijimos, es el primer factor que se consume en la coagulación y deberá ser repuesto en un paciente sangrando cuando este sea $<1,5-2 \mathrm{~g} / \mathrm{l}$. Las dosis iniciales de fibrinógeno comercial (Haemocomplettan $\left.{ }^{\circledR}\right)$ son de $25-50 \mathrm{mg} / \mathrm{kg}$ de peso ${ }^{(46)}$.

Si bien inicialmente los resultados fueron promisorios, se han publicado resultados contradictorios con respecto a sangrado y tasa de transfusiones ${ }^{(70)}$. Contrariamente, en Estados Unidos está considerado off-label (fuera de indicación aprobada), por lo que no está disponible en muchos centros.

Efecto rebote de heparina. Es descrito como el restablecimiento de un estado de heparinización después de haber revertido la heparina. Ocurre por una rápida distribución y aclaramiento de la protamina que lleva a la desunión con la heparina. También hay liberación de heparina de tejidos considerados sitios de almacenamiento (endotelio y tejido conectivo). Puede presentarse hasta seis horas después de finalizada la cirugía, y se detectan mediante el aumento de TCA y/o KPTT.

\section{Control del efecto de los nuevos anticoagulantes:}

Dabigatran. Su antídoto aprobado es el idarucizumab, un fragmento de anticuerpo monoclonal. Se administra en infusión IV rápida en dosis de $5 \mathrm{~g}$ (2 viales), con respuesta en 15 minutos. No es preciso corregir la dosis por insuficiencia renal o hepática. Contiene sorbitol; no debe usarse en pacientes intolerantes a lactosa.

Otra opción es la hemodiálisis.

Rivaroxabán, edoxabán y apixabán. Para controlar sus efectos contamos como antídoto con andexanet-alfa (reversión específica) en dosis de 400-800 mg en bolo IV en 15-30 minutos; hay que reiterarlo a las $2 \mathrm{~h}$.

Como intervenciones alternativas:

a) Complejo protrombínico 25-50 UI/kg.

b) Feiba (complejo protrombínico activado) 30-50 $\mathrm{U} / \mathrm{kg}$.

c) Factor VII (Novoseven ${ }^{\circledR}$ ) 90-100 $\mu \mathrm{g} / \mathrm{kg}$. Solo debe ser usado como último recurso, y debe recor- 
darse que puede ser efectivo si no hay hipotermia, hipocalcemia o hipofibrinogenemia.

Optimizar las condiciones básicas para una hemostasia competente

Evitar la hipotermia, manteniendo la temperatura central $>33^{\circ} \mathrm{C}$, calentando fluidos y recurriendo al uso de colchón y manta térmicos. Corregir la acidosis, procurando un $\mathrm{pH}>7,22$ mediante la modificación de parámetros del ventilador y uso de bicarbonato de sodio. Evitar la hipocalcemia, manteniendo el calcio iónico entre 4,4-5,2 mg/dl (1,1 -1,3 mmol/l), Manejo criterioso de la anemia, respetando la dosis máxima recomendada de coloides ${ }^{(71)}$.

Los trastornos de la hemostasia diagnosticada en el laboratorio sin sangrado, ya sea por los tests estándar o los point of care, no deben ser tratados, ya que su corrección no aporta beneficio, exponiendo a los pacientes al riesgo de inmunomodulación, infección, aloinmunización, etcétera ${ }^{(72,73)}$.

Hemostáticos tópicos. Diversas sustancias biocompatibles como fibrina, gelatinas y drogas son usadas en cirugía para mejorar la hemostasia cuando las suturas, la compresión o la electrocoagulación son insuficientes. Existen pocos estudios observacionales con escasa evidencia de mejora de estos productos, con los que se intenta dar un soporte al coágulo ${ }^{(74)}$.

El tratamiento del sangrado en estas cirugías comienza con la preparación del paciente en el preoperatorio y se intensifica en el intra y posoperatorio con una batería de medidas que deben ser adaptadas a cada paciente. Como corolario, la tabla 7 ordena globalmente los conceptos.

\section{Conclusiones}

Existe un grupo de pacientes con variadas patologías cardiovasculares que requieren $\mathrm{CC}$ convencional con CEC. La CC y especialmente la CEC generan diversos grados de activación del sistema inflamatorio de causa multifactorial, donde tienen un rol relevante las comorbilidades preexistentes. Varios son los sistemas y órganos blanco afectados por esta activación, en particular la hemostasia. Los avances actuales sobre fisiología, fisiopatología y nuevos sistemas de monitoreo han ampliado nuestro conocimiento sobre los mecanismos de la coagulación y sus alteraciones. Contamos con mayor disponibilidad de hemocomponentes y hemoderivados, recursos valiosos en el intento de recomponer la homeostasis de acuerdo a la evidencia. Sabemos de la existencia de predictores de sangrado, así como también que el principal tratamiento es la profilaxis. Finalmente, más allá de la existencia de guías, niveles de evidencia, protocolos de manejo y recursos disponibles, hay un grupo de pacientes que van a tener un sangrado aumentado que escapa a nuestra capacidad de predicción.

\section{Fernando Delgado,}

https://orcid.org/0000-0002-0137-3971

Washington Machado,

https://orcid.org/0000-0001-7689-4897

Gonzalo Machado,

https://orcid.org/0000-0003-3765-705X

Este artículo fue aceptado para su publicación por: Editor asociado Dr. Jorge Estigarribia

\section{Bibliografía}

1. Lyons A, Petrucelli J. Historia de la Medicina. Barcelona: Doyma, 1988.

2. Cohn L. Fifty years of open-heart surgery. Circulation. 2003; 107(17):2168-70. doi: 10.1161/01.CIR. 0000071746.50876.E2

3. Fondo Nacional de Recursos. Visualizador actos médicos realizados 2019. Montevideo: FNR, 2019. Disponible en: http://www.fnr.gub.uy/visualizador_realizaciones_2019. [Consulta: 9 Oct 2020].

4. Ferraris V, Ferraris $\mathbf{S}$, Saha $\mathbf{S}$, Hessel E, Haan C, Royston B, et al. Perioperative blood transfusion and blood conservation in cardiac surgery: the Society of Thoracic Surgeons and The Society of Cardiovascular Anesthesiologists clinical practice guideline. Ann Thorac Surg. 2007; 83(5 Suppl):S27-86. doi: 10.1016/j.athoracsur.2007.02.099

5. Carson J, Duff A, Poses R, Berlin J, Spence R, Trout R, et al. Effect of anaemia and cardiovascular disease on surgical mortality and morbidity. Lancet. 1996; 348(9034):1055-60. doi: 10.1016/S0140-6736 (96)04330-9

6. Kulier A, Levin J, Moser R, Rumpold-Seitlinger G, Tudor I, Snyder-Ramos S, et al. Impact of preoperative anemia on outcome in patients undergoing coronary artery bypass graft surgery. Circulation. 2007; 116(5):471-9. doi: 10.1161/CIRCULATIONAHA.106.653501

7. Kotecha D, Ngo K, Walters J, Manzano L, Palazzuoli A, Flather M. Erythropoietin as a treatment of anemia in heart failure: systematic review of randomized trials. Am Heart J. 2011; 161(5): 822-31.e2. doi: 10.1016/j.ahj.2011.02.013

8. Douketis J, Spyropoulos A, Spencer F, Mayr M, Jaffer A, Eckman M, et al. Perioperative management of antithrombotic therapy: Antithrombotic Therapy and Prevention of Thrombosis, 9th ed: American College of Chest Physicians Evidence-Based 
Clinical Practice Guidelines. Chest. 2012; 141(2 Suppl):e326S-50S. doi: 10.1378/chest.11-2298

9. Hall R, Mazer C. Antiplatelet drugs: a review of their pharmacology and management in the perioperative period. Anesth Analg. 2011; 112(2):292-318. doi: 10.1213/ANE.0b013e318203f38d

10. Ansell J, Hirsh J, Hylek E, Jacobson A, Crowther M, Palareti G. Pharmacology and management of the vitamin $\mathrm{K}$ antagonists: American College of Chest Physicians Evidence-Based Clinical Practice Guidelines (8th Edition). Chest. 2008; 133(6 Suppl):160S-98S. doi: 10.1378/chest.08-0670

11. Vázquez J, García Eleisequi R, Núñez H, Vives G. Circulación extracorpórea. En: Iglesias R, Pensa $\mathrm{C}$, eds. Cuidados perioperatorios en cirugía cardiovascular. Buenos Aires: Panamericana, 2000. p. 19-31.

12. Habib R, Zacharias A, Schwann T, Riordan C, Durham S, Shah A. Adverse effects of low hematocrit during cardiopulmonary bypass in the adult should current practice be changed? J Thorac Cardiovasc Surg. 2003; 125(6):1438-50. doi: 10.1016/ s0022-5223(02)73291-1

13. Woodman R, Harker L. Bleeding complications associated with cardiopulmonary bypass. Blood. 1990 76(9):1680-97. doi: 10.1182/blood.V76.9.1680.1680

14. Royston D, Kovesi T, Marczin N. The unwanted response to cardiac surgery: time for a reappraisal? $J$ Thorac Cardiovasc Surg. 2003; 125(1):32-5. doi: $10.1067 / \mathrm{mtc} .2003 .6$

15. Kestin A, Valeri C, Khuri S, Loscalzo J, Ellis P, MacGregor H, et al. The platelet function defect of cardiopulmonary bypass. Blood. 1993; 82(1):107-17. doi: 10.1182/blood.V82.1.107.bloodjournal821107

16. Weerasinghe A, Taylor K. The platelet in cardiopulmonary bypass. Ann Thorac Surg. 1998; 66(6):2145-52. doi: 10.1016/s0003-4975(98)00749-8

17. Holloway D, Summaria L, Sandesara J, Vagher J, Alexander J, Caprini J. Decreased platelet number and function and increased fibrinolysis contribute to postoperative bleeding in cardiopulmonary bypass patients. Thromb Haemost. 1988; 59(1):62-7 doi: $10.1055 / \mathrm{s}-0038-1646770$

18. Shibamiya A, Tabuchi N, Chung J, Sunamori M, Koyama T. Formation of tissue factor-bearing leukocytes during and after cardiopulmonary bypass. Thromb Haemost. 2004; 92(1):124-31. doi: 10.1160/TH03-12-0787

19. Spiess B, Silvay G. Overview of myocardial outcome: the interrelationships among coagulation, inflammation, and endothelium. J Cardiothorac Vasc Anesth. 2000; 14(3 Suppl 1):2-5.

20. Boer C, Meesters MI, Veerhoek D, Vonk ABA. Anticoagulant and side-effects of protamine in car- diac surgery: a narrative review. Br J Anaesth. 2018 May;120(5):914-927. doi: 10.1016/j.bja.2018.01.023.

21. Spiess B, Horrow J, Kaplan JA. Transfusion medicine and coagulation disorders. In: Kaplan JA, Reich DL, Konstadt SN. Cardiac Anesthesia. 4th ed. Philadelphia: WB Saunders Company, 1999.p. 1-14

22. Jakob S, Ensinger H, Takala J. Metabolic changes after cardiac surgery. Curr Opin Clin Nutr Metab Care. 2001; 4(2):149-55. doi: 10.1097/00075197-200103000-00012

23. Hennein H, Ebba H, Rodriguez J, Merrick S, Keith F, Bronstein M, et al. Relationship of the proinflammatory cytokines to myocardial ischemia and dysfunction after uncomplicated coronary revascularization. J Thorac Cardiovasc Surg. 1994; 108(4):626-35. doi: 10.1016/S0022-5223(94)70286-1

24. Menkis AH, Martin J, Cheng DC, Fitzgerald DC, Freedman JJ, Gao C, et.al. Drug, devices, technologies, and techniques for blood management in minimally invasive and conventional cardiothoracic surgery: a consensus statement from the International Society for Minimally Invasive Cardiothoracic Surgery (ISMICS) 2011. Innovations (Phila). 2012;7(4):229-41. doi: 10.1097/IMI.0b013e3182747699.

25. Teixeira, Guaracy Fernandes. Temas actuais em circulaçao extracorpórea. Porto Alegre: Sociedade Brasileira de Circulação Extracorpórea, 1997.

26. Despotis G, Joist J, Hogue C, Alsoufiev A, Kater K, Goodnough $\mathbf{L}$, et al. The impact of heparin concentration and activated clotting time monitoring on blood conservation: a prospective, randomized evaluation in patients undergoing cardiac operation. J Thorac Cardiovasc Surg. 1995; 110(1):46-54. doi: 10.1016/S0022-5223(05)80008-X

27. Lespron Robles M, Molina Méndez F. Terapia anticoagulante en la circulación extracorpórea. Arch Cardiol Méx. 2007; 77(Supl 4):185-93.

28. Paniagua P, Fita G, Rivera L, Parramon F, Koller T, Basora $\mathbf{C}$, et al. Prevención, diagnóstico y tratamiento de la hemorragia en cirugía cardiaca. Rev Esp Anestesiol Reanim. 2013; 6(3):149-60. doi: 10.1016/j.redar.2012.09.015

29. Dunning J, Versteegh M, Fabbri A, Pavie A, Kolh P, Lockowandt U, et al. Guideline on antiplatelet and anticoagulation management in cardiac surgery. Eur J Cardiothorac Surg. 2008; 34(1):73-92. doi: 10.1016/j.ejcts.2008.02.024

30. Mannucci P. Hemostatic drugs. N Engl J Med. 1998; 339(4):245-53. doi: 10.1056/NEJM199807233390407

31. Ker K, Edwards P, Perel P, Shakur H, Roberts I. Effect of tranexamic acid on surgical bleeding: systematic review and cumulative meta-analysis. BMJ 2012; 344:e3054. doi: 10.1136/bmj.e3054

32. Henry D, Carless P, Moxey A, O'Connell D, Stokes B, Fergusson D, et al. Anti-fibrinolytic use for minimi- 
sing perioperative allogeneic blood transfusion. Cochrane Database Syst Rev. 2011; 2011(3):CD001886. doi: 10.1002/14651858.CD001886.pub4

33. McEvoy M, Reeves S, Reves J, Spinale F. Aprotinin in cardiac surgery: a review of conventional and novel mechanisms of action. Anesth Analg. 2007; 105(4):949-62. doi: 10.1213/01.ane.0000281936 $04102.9 f$

34. Fergusson D, Hébert P, Mazer C, Fremes S, MacAdams C, Murkin J, et al. A comparison of aprotinin and lysine analogues in high-risk cardiac surgery. N Engl J Med. 2008; 358(22):2319-31. doi 10.1056/NEJMoa0802395

35. Karkouti K, Wijeysundera D, Yau T, McCluskey S, Tait G, Beattie W. The risk-benefit profile of aprotinin versus tranexamic acid in cardiac surgery. Anesth Analg. 2010; 110(1):21-9. doi: 10.1213/ ANE.0b013e3181c0ea6d

36. Murkin J, Falter F, Granton J, Young B, Burt C, Chu M. High-dose tranexamic Acid is associated with nonischemic clinical seizures in cardiac surgical patients. Anesth Analg. 2010; 110(2):350-3. doi: 10.1213/ANE.0b013e3181c92b23

37. Segal J, Dzik W; Transfusion Medicine/Hemostasis Clinical Trials Network. Paucity of studies to support that abnormal coagulation test results predict bleeding in the setting of invasive procedures: an evidence-based review. Transfusion. 2005; 45(9):1413-25. doi: 10.1111/j.1537-2995.2005.00546.x

38. Despotis G, Gravlee G, Filos K, Levy J. Anticoagulation monitoring during cardiac surgery: a review of current and emerging techniques. Anesthesiology. 1999; 91(4):1122-51. doi: 10.1097/00000542-1999 10000-00031

39. Luddington R. Thromboelastography/thromboelastometry. Clin Lab Haematol. 2005; 27(2):81-90. doi: 10.1111/j.1365-2257.2005.00681.x

40. Ogawa S, Szlam F, Chen E, Nishimura T, Kim H, Roback J, et al. A comparative evaluation of rotation thromboelastometry and standard coagulation tests in hemodilution-induced coagulation changes after cardiac surgery. Transfusion. 2012 52(1):14-22. doi: 10.1111/j.1537-2995.2011.03241.x

41. Davidson S, McGrowder D, Roughton M, Kelleher A. Can ROTEM thromboelastometry predict postoperative bleeding after cardiac surgery? J Cardiothorac Vasc Anesth. 2008; 22(5):655-61. doi: 10.1053/j.jvca.2008.07.002

42. Williams B, McNeil J, Crabbe A, Tanaka K. Practical Use of Thromboelastometry in the Management of Perioperative Coagulopathy and Bleeding. Transfus Med Rev. 2017; 31(1):11-25. doi 10.1016/j.tmrv.2016.08.005

43. Avidan M, Alcock E, Da Fonseca J, Ponte J, Desai J, Despotis G, et al. Comparison of structured use of routine laboratory tests or near-patient assessment with clinical judgement in the management of bleeding after cardiac surgery. Br J Anaesth. 2004; 92(2):178-86. doi: 10.1093/bja/aeh037

44. Anderson L, Quasim I, Soutar R, Steven M, Macfie A, Korte W. An audit of red cell and blood product use after the institution of thromboelastometry in a cardiac intensive care unit. Transfus Med. 2006; 16(1):31-9. doi: 10.1111/j.1365-3148.2006.00645.x

45. Despotis G, Avidan M, Eby C. Prediction and management of bleeding in cardiac surgery. J Thromb Haemost. 2009; 7(Suppl 1):111-7. doi: 10.1111/j. 1538-7836.2009.03412.x

46. Bhardwaj V, Kapoor P. Platelet aggregometry interpretation using ROTEM - PART - II. Ann Card Anaesth. 2016; 19(4):584-6. doi: 10.4103/0971-9784. 191559

47. Dyke C, Aronson S, Dietrich W, Hofmann A, Karkouti K, Levi M, et al. Universal definition of perioperative bleeding in adult cardiac surgery. $\mathrm{J}$ Thorac Cardiovasc Surg. 2014; 147(5):1458-63.e1. doi: 10.1016/j.jtcvs.2013.10.070

48. Ranucci M, Baryshnikova E, Castelvecchio S, Pelissero G; Surgical and Clinical Outcome Research (SCORE) Group. Major bleeding, transfusions, and anemia: the deadly triad of cardiac surgery. Ann Thorac Surg. 2013; 96(2):478-85. doi: 10.1016/j.athoracsur.2013.03.015

49. Ferraris V, Hochstetler M, Martin J, Mahan A, Saha S. Blood transfusion and adverse surgical outcomes: The good and the bad. Surgery. 2015; 158(3):608-17. doi: 10.1016/j.surg.2015.02.027

50. Likosky D, Zhang M, Paone G, Collins J, DeLucia A, Schreiber T, et al. Impact of institutional culture on rates of transfusions during cardiovascular procedures: The Michigan experience. Am Heart J. 2016; 174:1-6. doi: 10.1016/j.ahj.2015.12.019

51. O'Connell K, Wood J, Wise R, Lozier J, Braun M. Thromboembolic adverse events after use of recombinant human coagulation factor VIIa. JAMA. 2006; 295(3):293-8. doi: 10.1001/jama.295.3.293

52. Moulton M, Creswell L, Mackey M, Cox J, Rosenbloom M. Reexploration for bleeding is a risk factor for adverse outcomes after cardiac operations. J Thorac Cardiovasc Surg. 1996; 111(5):1037-46. doi: 10.1016/s0022-5223(96)70380-x

53. Karkouti K, Wijeysundera D, Beattie W, Callum J, Cheng D, Dupuis J, et al. Variability and predictability of large-volume red blood cell transfusion in cardiac surgery: a multicenter study. Transfusion. 2007; 47(11):2081-8. doi: 10.1111/j.15372995.2007.01432.x

54. Karthik S, Grayson A, McCarron E, Pullan D, Desmond M. Reexploration for bleeding after coronary artery bypass surgery: risk factors, outcomes, 
and the effect of time delay. Ann Thorac Surg. 2004;78(2):527-34. doi: 10.1016/j.athoracsur.2004. 02.088

55. Murphy G, Pike K, Rogers C, Wordsworth S, Stokes E, Angelini G, et al. Liberal or restrictive transfusion after cardiac surgery. N Engl J Med. 2015; 372(11):997-1008. doi: 10.1056/NEJMoa 1403612

56. Hajjar L, Vincent J, Galas F, Nakamura R, Silva $\mathbf{C}$, Santos M, et al. Transfusion requirements after cardiac surgery: the TRACS randomized controlled trial. JAMA. 2010; 304(14):1559-67. doi: 10.1001/jama.2010.1446

57. Lacroix J, Hébert $\mathbf{P}$, Fergusson D, Tinmouth A, Cook D, Marshall J, et al; ABLE Investigators; Canadian Critical Care Trials Group. Age of transfused blood in critically ill adults. N Engl J Med. 2015; 372(15):1410-8. doi: 10.1056/NEJMoa1500704

58. Sartipy U, Holzmann M, Hjalgrim H, Edgren G. Red Blood Cell Concentrate Storage and Survival After Cardiac Surgery. JAMA. 2015; 314(15):1641-3. doi: 10.1001/jama.2015.8690

59. Alexander P, Barty R, Fei Y, Vandvik P, Pai M, Siemieniuk R, et al. Transfusion of fresher vs older red blood cells in hospitalized patients: a systematic review and meta-analysis. Blood. 2016; 127(4):400-10. doi: 10.1182/blood-2015-09-670950

60. Vamvakas E, Blajchman M. Transfusion-related immunomodulation (TRIM): an update. Blood Rev 2007; 21(6):327-48. doi: 10.1016/j.blre.2007.07.003

61. Blumberg N, Zhao H, Wang H, Messing S, Heal J, Lyman G. The intention-to-treat principle in clinical trials and meta-analyses of leukoreduced blood transfusions in surgical patients. Transfusion. 2007; 47(4):573-81. doi: 10.1111/j.1537-2995.2007.01158.x

62. Rohde J, Dimcheff D, Blumberg N, Saint S, Langa K, Kuhn L, et al. Health care-associated infection after red blood cell transfusion: a systematic review and meta-analysis. JAMA. 2014; 311(13):1317-26. doi: 10.1001/jama.2014.2726

63. Engels G, van Klarenbosch J, Gu Y, van Oeveren W, de Vries A. Intraoperative cell salvage during cardiac surgery is associated with reduced postoperative lung injury. Interact Cardiovasc Thorac Surg. 2016; 22(3):298-304. doi: 10.1093/icvts/ivv355

64. Kaufman R, Djulbegovic B, Gernsheimer T, Kleinman S, Tinmouth A, Capocelli K, et al. Platelet transfusion: a clinical practice guideline from the AABB. Ann Intern Med. 2015; 162(3):205-13. doi: 10.7326/M14-1589

65. Kozek-Langenecker S, Ahmed A, Afshari A, Albaladejo P, Aldecoa C, Barauskas G, et al. Management of severe perioperative bleeding: guide- lines from the European Society of Anaesthesiology: First update 2016. Eur J Anaesthesiol. 2017; 34(6):332-95. doi: 10.1097/EJA.0000000000000630

66. Vivas D, Roldán I, Ferrandis R, Marín F, Roldán V, Tello-Montoliu A, et al. Manejo perioperatorio y periprocedimiento del tratamiento antitrombótico: documento de consenso de SEC, SEDAR, SEACV, SECCV. AEC, SECPRE, SEPD, SEGO, SEHH, SETH, SEMERGEN, SEMFYC, SEMG, SEMICYUC. SEMI, SEMES, SEPAR, SENEC, SEO, SEPA, SERVET, SECC Y AEU. Rev Esp Cardiol. 2018; 71(7):553-64. doi: 10.1016/j.recesp.2018.01. 001

67. Desborough M, Sandu R, Brunskill S, Doree C, Trivella M, Montedori A, et al. Fresh frozen plasma for cardiovascular surgery. Cochrane Database Syst Rev. 2015; (7):CD007614. doi: 10.1002/14651858.CD007614.pub2

68. Boer C, Meesters M, Milojevic M, Benedetto U, Bolliger D, von Heymann C, et al. 2017 EACTS/EACTA Guidelines on patient blood management for adult cardiac surgery. J Cardiothorac Vasc Anesth. 2018; 32(1):88-120. doi: 10.1053/j. jvca.2017.06.026

69. Casbard A, Williamson L, Murphy M, Rege K, Johnson T. The role of prophylactic fresh frozen plasma in decreasing blood loss and correcting coagulopathy in cardiac surgery. A systematic review. Anaesthesia. 2004; 59(6):550-8. doi: 10.1111/j. 1365-2044.2004.03711.x

70. Rahe-Meyer N, Levy J, Mazer C, Schramko A, Klein A, Brat R, et al. Randomized evaluation of fibrinogen vs placebo in complex cardiovascular surgery (REPLACE): a double-blind phase III study of haemostatic therapy. $\mathrm{Br} \mathrm{J}$ Anaesth. 2016; 117(1):41-51. doi: 10.1093/bja/aew169

71. Van der Linden P, Ickx B. The effects of colloid solutions on hemostasis. Can J Anaesth. 2006; 53(6 Suppl):S30-9. doi: 10.1007/BF03022250

72. Görlinger K, Shore-Lesserson L, Dirkmann D, Hanke A, Rahe-Meyer N, Tanaka K. Management of hemorrhage in cardiothoracic surgery. J Cardiothorac Vasc Anesth. 2013; 27(4 Suppl):S20-34. doi: 10.1053/j.jvca.2013.05.014

73. Davidson S. State of the art: how I manage coagulopathy in cardiac surgery patients. Br $\mathrm{J}$ Haematol. 2014; 164(6):779-89. doi: 10.1111/bjh.12746

74. Cheikh A, Ajaja M, Rhazali H, Bouatia M, Benomar A, Slaoui A, et al. Contribution of fibrin glue in the surgery of cyanogenic and non-cyanogenic congenital cardiopathies: retrospective cohort study. BMC Cardiovasc Disord. 2019; 19(1):117. doi: 10.1186/s12872-019-1102-7 